\title{
DIÁLOGO REFLEXIVO Y COMPROMISO EXISTENCIAL
}

\section{P. Rafael Sánchez, cp.}

En la conocida novela La Conjura de los necios, del escritor estadounidense Kennedy Toole, una violenta sátira de la sociedad norteamericana, el protagonista, Ignatius J. Reilly (representa, en cierta manera, al espíritu crítico en grado superlativo), sostiene una mirada del mundo tétrica, cruel y sórdida. Su madre, la señora Reilly ( simboliza a la intuición), cansada del comportamiento extravagante y díscolo del hijo, llega a decirle: "Con todo lo que he hecho siempre por ti, lo único que tú haces es tratarme a patadas. Quiero que alguien me trate bien antes de morir. Lo aprendiste todo, Ignatius, todo, salvo cómo debe comportarse un ser humano" (Kennedy Toole, 1992: 334). Palabras fuertes y profundas que ponen en evidencia la falta de complementación entre el conocimiento adquirido (saber objetivo) y la aplicación del mismo en la construcción de la existencia con los demás (convivir y comunicarse con sabiduría y verdad, desde la belleza y la bondad humana) y el modo de estar en el mundo. El conocimiento de la realidad ha de ir de la mano con el modo de vivir humanizador. No siempre el que 'mucho sabe' (sea un conocimiento enciclopédico o especializado), 'comprende la realidad' y actúa en ella con sabiduría y excelencia. En este sentido, sin

\footnotetext{
* Sacerdote pasionista. Licenciado en Filosofía Pura por la Universidad Complutense de Madrid (España).
} 
desdeñar el saber diversificado (saber especialista de cada ciencia), la filosofía se ocupa esencialmente del saber de la totalidad. La tendencia actual a 'prescindir' o 'subestimar' la filosofía, fomenta la negligencia, la apatía y la insipidez hacia el ejercicio del pensar en sí mismo y el imperativo de vivir y convivir en el mundo. Las facultades superiores del hombre (el entendimiento, cuyo objeto formal es el ente en cuanto ente [el ser]; la voluntad, cuyo objeto formal es el bien; la libertad, propiedad de la facultad volitiva], convergen hacia un mismo horizonte intelectual y práctico: la comprensión de la realidad y el acto de vivir en la cotidianidad. Afirma el profesor Maceiras:

La filosofía como reflexión, por el contrario, no puede ser sino capacitación para que el hombre piense y actúe con la mayor clarividencia posible, cada día más liberado de las distorsiones que provienen de su constitución psíquica, de la vida cotidiana, del ámbito social y de la comunicación, de los intereses de todo tipo. Es esta la practicidad de la filosofía que debe ser ejercitada día a día como condición de una vida legítimamente humana (Maceiras, 1994).

A partir de lo anterior, en donde se ha hecho mención a la estrecha relación que ha de haber entre el pensamiento y la acción (el encuentro del hombre con lo real), cabe formular la siguiente pregunta: ${ }_{i}$ Puede darse por satisfecho el profesor de filosofía de haber enseñado, en la hora de clase, cuando el alumno no ha sintonizado con él, debido a su falta de interés e indiferencia por la materia? Siendo más explícitos: ¿̇se aprende filosofía exclusivamente por lo que enseña el profesor o por la disposición del alumno a la voluntad de comprender la materia? Ciertamente, tanto en el ejercicio de enseñar como de aprender filosofía, se cuenta necesaria e inexcusablemente con la totalidad de la persona. 
El objeto material [el 'quod'] del presente artículo tiene que ver con los actores, su relación y participación en el proceso didáctico de la enseñanza-aprendizaje de la filosofía. A su vez, el objeto formal [el 'quo'] va a consistir en estudiar el tema desde la reciprocidad reflexiva (docente y alumno) y su consiguiente incidencia en la realidad (lección de vida). En cuanto al método, partiremos de unos esquemas prelógicos con los que inferir esquemas de discurso de doble contenido: discurso de comprensión (la repercusión significativa de la filosofía en el ser humano) y, a modo de ensayo, el discurso teórico (destreza e inteligencia de enseñar/aprender filosofía).

\section{En camino}

No hace falta abrir demasiado los ojos para percatarse del protagonismo, sin parangón con otras etapas de la historia, que gozan la ciencia y la técnica en la sociedad actual. La demanda de aparatos electrónicos está en función con las ofertas comerciales y, ¿por qué no?, con las necesidades creadas para avalar la 'racionalidad' del producto, su importancia en la vida humana y su eficacia en el engranaje social y profesional. El homo ciberneticus no es un sencillo concepto con el que resaltar una cualidad humana, sino una inequívoca realidad a todas luces presente en los diferentes ámbitos del obrar humano (familia, trabajo, enseñanza, deporte, salud, etcétera). El hombre, fascinado por los logros obtenidos, rinde pleitesía al producto de sus manos, y confía sin restricciones en los medios técnicos, sin claudicar, por otra parte, a la mirada simbólica: "Y en el ser humano, el desarrollo del conocimiento racional-empírico-técnico no ha anulado el conocimiento simbólico, mítico, mágico o poético" (Morin, 2003: 57). La imagen $\mathrm{y}$ el sonido constituyen una ventana atractiva y atrayente 
en donde mirar la realidad, pero una realidad virtual y no tangible. Con sutileza, el ejercicio del pensar es desplazado (¿subordinado?) por la experiencia primaria del sentir, vibrar, emocionarse, disfrutar de lo que se ve y de lo que se oye. En este sentido, todo aquello que tiene que ver con el discurso reflexivo, con el análisis de lo dado (la exterioridad), con lo que está a la mano, con los acontecimientos humanos, los fenómenos culturales, en fin, con el pensamiento (principal instrumento de la filosofía), no llama la atención, siendo considerado poco práctico y, por ello, ubicado en la periferia de los intereses de muchas personas o relegado a una plano ínfimo. ¿Una vida sin reflexión puede garantizar una vida humana? ¿Qué queda del hombre si, por factores externos o iniciativas personales, se forja la existencia echando mano únicamente a las facultades sensitivas? ¿Qué cabe esperar de quien se sitúa en la vida como simple espectador o, lo que es más desconcertante, como un consumidor de productos de entretenimiento y de bienes fungibles? ¿En eso consiste la vida humana, el acto de vivir, el proyecto personal y la construcción social de la realidad? ¿Acaso no define Aristóteles al hombre como un 'zoón noéticon', un ser vivo que piensa?

Cuando Sócrates declaró que una vida sin reflexión no merecía la pena ser vivida, abogaba por la evaluación personal constante y el esfuerzo por mejorarse a sí mismo como la más alta de las vocaciones. [...] Las personas que luchan por hallar una manera de comprender y manejarse en un mundo que cada día es más complejo no tienen por qué verse etiquetadas con un trastorno, cuando lo que en realidad están haciendo es avanzar por caminos consagrados a la búsqueda de una vida más satisfactoria (Marinoff, 2000: 26).

En el contexto de la educación, y de manera particular, en la enseñanza de filosofía, el reto que se presenta 
es urgente y significativo. Urgente, en cuanto a la situación deplorable que se observa en el ambiente social, de marcada propensión a esquivar, por así decirlo, el ejercicio de la reflexión o, por el contrario, a practicar la reflexión de forma inconexa, arbitraria e intimista, confundiendo, en vez de aclarar; fragmentando, en vez de integrar; opinando a diestra y siniestra, en vez de guardar silencio y escuchar. Significativo, en cuanto a la tarea de hacer atractivo, inteligible y válido el saber filosófico, de tal suerte que despierte primero admiración, asombro, y segundo, convicción y constancia de dedicarse a ella. Edgar Morin reconoce que el empleo total de la inteligencia general "necesita el libre ejercicio de la facultad más expandida y más viva en la infancia y en la adolescencia: la curiosidad, la cual, muy a menudo, es extinguida por la instrucción, cuando se trata por el contrario, de estimularla o, si está dormida, de despertarla" (Morin, 2003:40). Teniendo en cuenta estos dos aspectos, vamos a desarrollar el tema de este número especial de la Colección SOPHIA [Enseñar y Aprender Filosofía], a partir del título que encabeza este artículo, a saber: diálogo reflexivo y compromiso existencial. La primera expresión 'sístole' desde el horizonte académico; la segunda 'diástole', empero, desde el horizonte de la existencia. Ambas expresiones se complementan armoniosamente de cara a proponer algunas pautas didácticas, sencillas, dirigidas a aquellos profesores que se dedican a enseñar filosofía e, incluso, para los docentes de las disciplinar correspondientes a las ciencias sociales y económicas.

\section{Dialógo reflexivo [sistole]}

El aula es un espacio en el que se da el encuentro entre dos o más individuos. Los diferentes modos de enseñanza, así como las lecciones (ver Perelló, 2008: 170-175), 
mantienen en común la dinámica del diálogo reflexivo que, según los matices específicos, el diálogo puede caracterizarse por ser unilateral (profesor al alumno) o bilateral (alumno y profesor).

\section{Los interlocutores: personajes}

Por una parte está el alumno; por otra, el profesor. Entre ambos se da el proceso didáctico enseñanza-aprendizaje. En cada clase, el profesor se encuentra con el alumno-curso y viceversa. La relación es de encuentro, en el que intervienen diferentes elementos que hacen del mismo una sinfonía de comunicación y convivencia, de diálogo reflexivo, donde el profesor no está por encima del alumno ni el alumno por debajo del profesor, sino que la distinción estriba en la competencia de los interlocutores (profesor: enseña; alumno: aprende la materia). El encuentro ha de ser flexible, cercano, auténtico, dinámico y creativo. Decir diálogo es suscitar en el alumno la participación (y no la sumisión), y en el profesor la escucha (y no el monólogo). Comenta el profesor López Quintás:

El hombre es un 'ser de de encuentro', debe encontrarse con todas las realidades que le rodean: familia, paisaje, obras culturales, tradiciones, usos, costumbres, valores de todo orden. La realización de estos modos de encuentro implica creatividad. Ser creativo significa asumir posibilidades de realizar acciones con sentido y fundar vínculos valiosos con las realidades circundantes (López Quintás, 1998: 187).

\section{El tema común: la filosofía}

Alumno y profesor contemplan al unísono el mosaico filosófico (nunca mejor dicho) para conocer, comprender y considerar las aportaciones de sus autores. 
Así como en un mosaico hay piezas de diferentes tamaños, formas y colores, igualmente, la historia de la filosofía está conformada de una variedad de sistemas filosóficos, de autores (algunos importantes, otros más modestos), de métodos, contenidos (objeto del conocimiento) y saberes con la secuencia origen-expansión-influencia posterior.

El mosaico no es cerrado, delimitado o circunscrito a ciertos cánones preestablecidos, sino abierto al proceso de rectificación de hipótesis y teorías en correspondencia con la realidad concreta. "Una teoría filosófica es más fructífera cuando sabe dar más aportes para la orientación teórica y práctica del hombre en la totalidad del universo" (Estermann, 2000: 22). La apertura de la filosofía sugiere la apertura del profesor y del alumno en el pensar. Por supuesto, una apertura crítica, con el fin de no atiborrarse de ideas sin ton ni son, sino de emprender el contacto con las corrientes del pensamiento que, a lo largo de la historia, han sido determinantes en la configuración de la sociedad y el auge cultural de cada época. En este sentido, la filosofía no es ajena al conjunto de realidades que tienen que ver con la 'concepción del universo'. La filosofía 'primera' (la metafísica: que estudia el ente) viene a ser el pentagrama que reúne las notas de los demás saberes filosóficos (filosofía 'segunda'). De aquí se deriva la estructura unitaria del saber filosófico. Alumno y profesor han de situarse frente a la unidad de la filosofía a la luz de los criterios de claridad, precisión, análisis, síntesis, argumento, rectificación y verdad. La filosofía no es un 'cajón de sastre' donde las cosas estás desordenadas, sino un 'fichero' donde están registrados ordenadamente los modos secundarios e imperfectos del saber filosófico. La filosofía comprende el ser (ontología); el hombre (antropología); los valores (ética) y la trascendencia (teodicea) ${ }^{1}$. Cuatro dimensiones que tienen que ver con la relación del hombre con el mundo, consigo mismo, con los demás y con Dios. Todas las piezas 
del mosaico tienen su importancia en el avance histórico de la filosofía. No se trata de destacar unas disciplinas a costa de rechazar a otras, sino de considerar a cada una (al igual que los diferentes sistemas filosóficos) a partir del entramado histórico (cultura, sociedad, política, religión, economía, etcétera) en que se fraguaron. La verdad o el error que haya podido haber en ellos, ha contribuido en la sustantividad y practicidad de la filosofía que, por cierto, en su historia, destaca el movimiento pendular Platón y Aristóteles.

Cada sistema filosófico puede valer como una respuesta a la pregunta de lo qué es la filosofía y también acerca de lo que la actividad filosófica representa para la vida humana. Cada una de estas respuestas es, por lo tanto, parcial. Pero al mismo tiempo es necesaria si tenemos en cuenta que la filosofía se va formando en el curso de su propia historia. [...]. Paradójicamente, la unidad de la filosofía -siempre que no interpretemos esta expresión en un sentido demasiado rígido o con excesivas resonancias hegeliana- se manifiesta a través de su diversidad (Ferrater Mora, 1994: 1272).

Nuestros protagonistas (alumno y profesor) han de habérselas con fechas, lugares, nombres, proposiciones, sistemas, disciplinas que tienen como fundamento y vértice a la filosofía. O si lo prefieren, han de afinar el oído para escuchar con inteligibilidad la melodía que interpreta las diferentes notas y registros en el pentagrama de la metafísica. Puede servirnos la imagen siguiente: el profesor es el director de orquesta; los alumnos, los músicos con sus respectivos instrumentos musicales, y la partitura a interpretar: un filósofo o una corriente filosófica. Tiene que ver con la vida en sí, con el mundo, el hombre y Dios, de tal suerte que el hombre se eleva a las cosas trascendentales mirando la realidad y actuando en ella desde una pers- 
pectiva y disposición interior renovadas, clarificadoras y transformadoras ${ }^{2}$.

\section{El desafio del docente: despertar en el alumno el gusto por la filosofía}

Más de un profesor de filosofía se habrá sentido frustrado, decepcionado, confundido y cansado al comprobar el poco interés que despierta esta ciencia universal (fundamental, racional y crítica) en sus alumnos y en la sociedad en general. Habrá quienes se preguntarán: ¿para qué sirve la filosofía?, ¿se puede alcanzar seguridad material con la filosofía?, ¿qué servicio puede prestar a la sociedad semejante disciplina?; el filósofo o el que se dedica a enseñar filosofía o el estudiante de filosofía, ¿no dan la sensación de estar en las nubes, entronizados en su yo racional, embelesados en sus pensamientos, resguardados en la torre de marfil de sus argumentos y dialécticas?, ¿no será que la filosofía está herida de muerte? Sería mucho decir. ¿La filosofía, en crisis? Tal vez. Ahora bien, la crisis hay que interpretarla en un sentido positivo y no peyorativo. En toda crisis subyace una importante dosis de esperanza y, por consiguiente, un beneficio para la filosofía, en cuanto a la exigencia inherente de ser significativa y decisiva en el universo disciplinar actual. El profesor tiene un gran reto por delante y, ¿por qué no?, en adelante, mucho más que en tiempos pretéritos: ha de lograr en el alumno el gusto por la filosofía. ¿Misión imposible? ¿Ideal inalcanzable? Vamos a ver...

Para Batista Libanio, jesuita, "corresponde al maestro estimular a sus discípulos, hacer que la vida intelectual les resulte atractiva, bien mediante su ejemplo personal de humanidad, bien mediante la belleza interior de esta vida" (2007: 152). Estamos de acuerdo en que la 'motivación didáctica' es la herramienta de la que tiene que 
echar mano el profesor de filosofía, para despertar en el alumno el interés por la materia. Pero, ¿qué hacer cuando el profesor pone de su parte, se esmera, y, sin embargo, el resultado es otro: la apatía del alumno? Julio Anguita, profesor de Ciencias Sociales de primero y segundo de E.S.O., en España (estuvo muchos años dedicado a la política), manifiesta al respecto:

No me vale el argumento de que a los alumnos 'hay que motivarles' porque se les incentiva constantemente, pero se muestran pasmosamente indiferentes. [...] Están sumidos en un constante presente y no les interesan asignaturas como la Filosofía o la Historia, que les ayudan a entender por qué ocurren las cosas. El trato que dispensan al profesor también es sorprendente. A veces hay falta de respeto hacia el que imparte clase, incluso como ser humano (Anguita, 2001: 43).

El profesor -el verdadero profesor-, esto es, aquel que vive su profesión como vocación, no solo como un medio de ganar dinero, aquel que, en la soledad y el silencio, dedica tiempo a preparar la clase y a su formación personal, se siente 'presionado' temporal o constantemente por tres frentes: 1. La institución en la que trabaja; 2. El alumno; 3. Los padres de familia. En el caso de los profesores universitarios la presión quedaría focalizada en los dos primeros frentes. Ahora bien, hay un cuarto frente que ampara y dirige la enseñanza del país: el Ministerio de Educación. Una instancia civil que tiene la tarea de salvaguardar los derechos y deberes de los ciudadanos en lo que a la enseñanza se refiere.

Nuestro profesor no ignora el hecho de que el alumno, al igual que él, es hijo de una época concreta, de una sociedad con sus tendencias culturales específicas y que, lejos de favorecer y legitimar la enseñanza de filosofía, 
la obstaculizan y subestiman. No pocas veces, se ha encontrado con:

- La resistencia del alumno: "Muchos alumnos tienen una serie de prejuicios sobre la clase de filosofía y una cierta predisposición al rechazo, debido a las informaciones que reciben de sus compañeros. Por otra parte se cuestiona la utilidad de la asignatura para su vida futura y para su trabajo" (Perelló, 2008: 166).

- La influencia de dos rasgos dominantes en la sociedad: el mercado y la competitividad. "Rige una mala interpretación de la democracia que busca el achusmamiento o aplebeyamiento de todos. Los jóvenes, hoy, no encuentran sentido a la reflexión, hecho que, además, se alienta con el modelo que proponen ciertos programas de televisión. Estamos perdiendo la dimensión ética y estética de la sociedad porque no interesa crear personas mejores, sino consumidores" (Anguita, 2001: 43).

El profesor de filosofía ha de tener en cuenta, que la calidad de su enseñanza radica en el grado de interés que manifieste por dar clases de filosofía. Él tiene que aplicarse a sí mismo la 'motivación didáctica'. ¿Cómo motivar al alumno desde la desmotivación del profesor, de la falta de convicción y entusiasmo de su parte? Contenido y metodología van de la mano, como el objeto material con el objeto formal. La claridad en la exposición de los contenidos, está en relación con la precisión de lo que se enseña, evitando a toda costa un lenguaje extremadamente obtuso, incierto y equívoco. No se trata de que el profesor haga ostentación frente al alumno de sus grandes dotes en el dominio de la materia, sino, lisa y llanamente, de hacer despertar en él el gusto por la filosofía. ¿Cómo? Haciéndole ver que no es una ciencia ajena a la vida porque, precisamente, es huma- 
na (privativa del hombre). El cultivo de la filosofía favorece la acción humanizadora del hombre en la sociedad y en la naturaleza. "Lo que mueve al alumno a tener interés por determinados contenidos del aprendizaje es el 'descubrir' que dicho contenido es un verdadero valor para la persona (que vale para él)" (Perelló, 2008: 161).

Conforme a lo que hemos visto hasta ahora, sobre el desafío del profesor, lo primero que tiene que incentivar el docente es la motivación en sí mismo y, a continuación, en el alumno. Que sea capaz de traducir a un lenguaje más asequible a las condiciones y capacidades del alumno el universo filosófico, haciéndole caer en cuenta que, si bien en la filosofía destaca la actividad esencialmente especulativa, no por eso vive a espaldas de la vida ordinaria. Aunque parezca ser la más inútil de todas las ciencias [su interés versa sobre las causas y principios de las cosas], no por eso está desprovista de valor. Tiene valor y un valor altamente 'iluminador', 'saludable' y 'operativo', en sí mismo para el hombre (ser precario), convirtiéndose, en este sentido, en "el máximo arbitrio natural que el hombre dispone para remediar su deficiencia entitativa" (Puelles, 1972: 35). El profesor tiene que acompañar al alumno hacia el 'amor a la sabiduría' (filosofía), no por la vía de la imposición, sino de la exposición; no con un lenguaje oscuro y rígido, sino claro y flexible; no con el monólogo, sino con el diálogo; no dando un rodeo (circunloquio), sino yendo al grano; no solo desde la verticalidad de la teoría, sino también en la horizontalidad de la práctica. "La filosofía ha proporcionado herramientas que las personas puedan usar en la vida cotidiana. [...]. La filosofía, al principio, era una forma de vida, no una disciplina académica; es decir, no solo objeto de estudio sino también aplicación” (Marinoff, 2000: 21).

Sin el propósito de dar una receta mágica en cuanto a cómo el profesor puede conseguir, con éxito, que 
el alumno muestre interés por la filosofía, 'se motive', señalamos cuatro sencillas orientaciones: 1. Que no decaiga el entusiasmo y la disponibilidad de impartir la materia, pese al ambiente de indiferencia que pueda reinar en el curso (y en la sociedad); 2. Conducir, o mejor, acompañar al alumno a que se interese por la filosofía. Por lo menos, que llegue a comprender su sentido y alcance en la vida humana, en la sociedad y en el mundo; 3. En sintonía con Batista Libanio, que dé 'ejemplo personal de humanidad'; ${ }^{3}$ Que no baje la guardia en lo que concierne a la formación permanente, con el fin de que pueda plasmar en el ejercicio de la docencia los rasgos que señala Julio Perelló: la reflexión crítica, el rigor de la interpretación, el orden y la sistematización del pensamiento, la capacidad de penetración y de iluminación de la realidad (2008: 163).

Esta primera parte trata del 'diálogo reflexivo', lo cual remite a dos interlocutores. Hemos tratado del desafío del profesor. No solo depende de él la calidad y el éxito de la enseñanza de filosofía, sino también del alumno. Es una tarea compartida porque el tema a estudiar es el mismo para ambos, el punto de referencia.

El desafío del alumno: estimular en el docente la articulación del rigor metodológico con la creatividad pedagógica

La observación del profesor Anguita, mencionada en el apartado anterior, pone el dedo en la llaga al decir que, en muchos alumnos, se observa dejadez hacia determinadas materias, pese a que el profesor se esmera por hacerlas interesantes, accesibles y permeables (en concreto, con la asignatura que nos incumbe, la filosofía).

Pueda ser que alguien considere el desafío del alumno 'demasiado elevado y poco acorde a sus capacidades y estado'. La objeción resbalaría y se perdería por el resquicio de la desestimación hacia el alumno y el re- 
celo a sus intervenciones. En el apartado acerca de los personajes, dijimos que entre el profesor y el alumno se da el proceso didáctico enseñanza-aprendizaje, donde el profesor enseña y el alumno aprende. Completamos esta aseveración manifestando que también el profesor puede aprender del alumno. Por ejemplo, con las preguntas que le formula, obligándole a ser claro, preciso y diligente en las respuestas, que han de estar centradas en el tema planteado y no irse por la tangente. El alumno no espera del profesor que sea infalible en sus comentarios, explicaciones y disquisiciones, sino que proceda con honradez intelectual y humildad pedagógica. No está obligado a saberlo todo, ni mucho menos a tener la razón en todo. Como dice certeramente un autor, "los mejores profesores -los que ejercen influencia más duradera en los alumnos- son los que saben confesar a veces: 'No lo sé', y no los que siempre se salen con la suya, aunque sea mediante piruetas" (Barlow, 1988: 139).

Así pues, si al alumno se le confía el desafío de estimular en el docente la articulación del rigor metodológico con la creatividad pedagógica, en correspondencia, él tiene que implicarse en la dinámica pedagógica, mostrar interés por la materia, participar responsablemente en el aprendizaje, reconocer con sencillez que tiene obligaciones y no únicamente derechos. El desafío del alumno hace de él un sujeto activo que interactúa con el profesor y con el resto de sus compañeros. Por supuesto, sus intervenciones no han de reducirse a opiniones personales basadas en la experiencia inmediata y espontánea, sino que han de tener orden, sentido y dirección o, si se prefiere, fundamento (argumento razonable). No se trata de decir lo primero que se le ocurra, sino considerar, preguntar, sugerir a partir del ejercicio del pensar4. Al profesor le compete dotar al alumno de los conceptos básicos y principios formales con los que familiarizarse con la filosofía y, de ese modo, 
'salir de sî́ para ver la realidad y comprenderla, convivir con los demás en la acogida y el diálogo, en otras palabras, ser persona y humanizar la realidad en la que vive inmerso. La filosofía puede ser de provecho, desde el punto de vista práctico, en los niños y adolescentes, para resolver determinados conflictos personales. Precisamente, "entre las grandes instancias educativas está la filosofía verdadera. En la edad ideal de la adolescencia, resulta infinitamente decisiva y puede enderezar muchas situaciones psicológicas y morales que comprometieron gravemente el destino de la persona” (Nicolas, 1991: 56).

Cada alumno es diferente y el ritmo de aprendizaje varía, debido a diferentes factores (psicológicos, familiares, culturales, económicos, etcétera). Hay alumnos más propensos a participar, y otro, por su perfil psicológico, más proclives a pasar desapercibidos, a no llamar la atención, a no intervenir, sea por timidez, por no saber expresarse o qué decir, por no dominar la materia a fondo. El profesor tiene que acompañar a cada alumno en su singularidad, sin dejarse llevar por la comparación. A su vez, el alumno, tiene que dejarse ayudar, acompañar, para alcanzar el conocimiento elemental, lo esencial, lo que está al alcance de todos con tal que haga un mínimo esfuerzo ${ }^{4}$. No es suficiente con 'asistir a clase', hay que 'participar en clase', vibrar intelectual y didácticamente con el contenido (materia), en diálogo con las condiciones subjetivas en él, que le impulse a la 'autoactividad' y, por consiguiente, al diálogo reflexivo con el profesor, a quien tiene que ver como un amigo que lo acompaña por el sendero del saber (conocimiento), la actividad de comprender (realidad) y educación de ser (persona), en la verdad, el bien y la integridad.

El alumno tiene que sintonizar con el profesor, que se preocupa por hacer la filosofía inteligible y apasionante, comunicando que es una ciencia "como algo capaz de ser entendido en muy diferentes niveles. Cual sucede 
con ciertas obras de arte, sería deseable que el pensamiento filosófico fuese elaborado, y sobre todo expuesto, de tal modo que muy diferentes clases de humanos, pudieran sentirse cautivados por él, cada uno según su talante y de acuerdo con sus propias capacidades" (Ferrater Mora, 1963: 171-172).

¿Qué se espera del alumno para que anime al docente a impartir la clase con calidad pedagógica? Desde luego, no se espera de él 'plenitud de saber' (¿qué ser humano lo ha alcanzado?), ni sumisión, sino apertura y colaboración, a partir de su edad, rasgos psicológicos y aptitudes para el aprendizaje. Del alumno cabe esperar: 1. Que esté motivado a aprender filosofía, no solo por influencia del profesor (para complacerlo por interés o miedo), sino por sí mismo; 2. Que, antes de rechazar la materia, tenga la audacia estudiantil y la voluntad de saber de qué va, qué contiene y cuál es su incidencia en la vida humana; 3. Que esté convencido de que, ya sea con esta materia o con cualquier otra, no se pierde el tiempo y su temática no es 'a destiempo’; 4. Que se considere sujeto actor en las clases de filosofía (siendo el objetivo de su estudio enseñar a pensar) y valore la figura del profesor como alguien que le acompaña en el proceso educativo y le ayuda (en libertad responsable) a conocer, comprender y aplicar las aportaciones de la filosofía en el contexto de la condición humana, el mundo y la cultura. El binomio enseñanza-aprendizaje no es hermético y unilateral (del profesor al alumno), sino abierto y bilateral (alumno y profesor) ${ }^{5}$.

Caminar juntos en la búsqueda corresponsable de comprender la verdadera realidad

El apartado precedente concluyó haciendo énfasis en la relación complementaria entre el alumno y el profesor, protagonistas del proceso didáctico enseñanza- 
-aprendizaje. En ellos, se cumple el concepto de reciprocidad, de correspondencia mutua de alumno y profesor que caminan juntos en la búsqueda corresponsable de comprender la verdadera realidad. El profesor tiene la ventaja, con respecto al alumno, de conocer estructural y sistemáticamente la materia que imparte. El alumno, a su vez, tiene la ventaja de poseer un pensamiento inductivo, en contacto directo con el entorno en el que vive y, por consiguiente, capaz de percibir aquellas 'señales culturales' que escapan, muchas veces, al control de una mente autosuficiente, desconfiada y formalista. Se trata de conectar el conocimiento formal (riguroso) del profesor de filosofía con la interpelación vivencial (espontánea) del alumno. ¿Qué tiene que decir la filosofía de la violencia, la guerra, la ambición de poder, la ciencia, la política o la cultura cuando prescinden de la dimensión ética? ¿Qué es el hombre? ¿En qué consiste conocer? ¿Tiene sentido la vida? ¿Por qué el sufrimiento, el dolor y la muerte? ¿Cómo explicar las constantes antropológicas: la autoconciencia, la alteridad, el tiempo, la historia y la trascendencia? En todas estas preguntas subyace una misma noción: la 'verdad', o lo 'verdadero'. El Papa Juan Pablo II define al hombre como "aquel que busca la verdad" (Juan Pablo II, 1998: n. 28) .

Por consiguiente, la tarea del profesor con el alumno [enseñanza], como la del alumno con el profesor [aprendizaje] confluye hacia un mismo objetivo: buscar la verdad. En este sentido, ni el profesor ha de pretender engañar, confundir, atolondrar al alumno en cuanto a la filosofía se refiere, ni el alumno ha de aspirar a hacer trampas, despistar, fingir que sabe la materia cuando no es cierto. En los dos interlocutores tiene que brillar la franqueza, el espíritu de colaboración y la voluntad de descubrir cómo son y están verdaderamente las cosas.

El diálogo reflexivo no es para eludir la realidad, así como tampoco la filosofía influye en los interlocuto- 
res (alumno y profesor) a modo de sedante o de somnífero, que neutraliza o minimiza la acción de ellos en la realidad. ¿Qué cabría esperar de un mundo donde el ser humano haya desistido a pensar, haya claudicado en el ejercicio de preguntar en torno a la dimensión constitutiva de la realidad, sobre el fundamento de las cosas, por el arjé (o arché): el principio de todas las cosas, aquello por lo que las cosas son lo que son? Cuando el profesor expone la filosofía sistemática en su desarrollo histórico, las respuestas que han dado los diferentes sistemas filosóficos con respecto a la naturaleza humana, sitúa al alumno ante el horizonte de algo elemental e iluminador: hombres de diferentes culturas y épocas, se han dedicado a dar una explicación definitiva (no sometida a la duda) a los interrogantes universales sobre el sentido de la propia existencia. Cada filósofo, cada corriente del pensamiento, han salido al paso de esas preguntas y ha aportado 'su verdad', habiendo sido analizada, aceptada, corregida o ampliada por sus contemporáneos o por las generaciones posteriores, con la finalidad de asentar la vida en una verdad aceptada como definitiva. Se trata de un trabajo conjunto, comprometido y constante. Asevera el Papa Juan Pablo II que "la sed de verdad está tan radicada en el corazón del hombre que tener que prescindir de ella comprometería la existencia” (Juan Pablo II, 1998: n. 29). El profesor y el alumno no buscan la verdad sin más en el conocimiento teórico de la realidad, sino también en su orientación práctica (actividad humana y valores).

Hay que conocer, comprender, considerar y aplicar. ¿Será posible que el alumno corone el último paso de la secuencia [aplicar], siendo así que su preocupación principal está en aprobar la materia de filosofía y no en contemplarla como un medio valioso de aupar y perfeccionar su humanidad? 


\section{Compromiso existencial [diástole]}

El aprendizaje y la enseñanza de la filosofía, comprometen a los sujetos del proceso didáctico. Aprender filosofía no consiste en almacenar a modo de silo nombres, fechas, lugares y sistemas de pensamiento para, a renglón seguido, exhibir la abundancia de información retenida por el alumno o concentrada en el profesor. Todos esos datos o elementos en la dinámica de conocer, han de tener otra orientación que la meramente formal, cronológica, geográfica y cuantitativa, esto es: "la comprensión de cuanto existe y el compromiso existencial en el mundo donde se está". Ignatius, el personaje literario mencionado al inicio de este artículo, sabía muchas cosas, había leído cantidad y variedad de libros, pero, ¿para qué? Tanto saber exuberante $y$, paradójicamente, exigua capacidad para comportarse como un ser humano.

Las diferentes disciplinas del saber, incluso las que, a primera vista, se presentan ásperas y obtusas, aportan una luz que esclarece, resuelve y define alguna dimensión humana, cognitiva y existencialmente hablando. En otras palabras, ayuda en la vida de los hombres. Un ejemplo lo hallamos en el matemático y economista estadounidense John Forbes Nash que, en 1944, recibió el premio Nobel de Economía, compartido con J. C. Harsanyi y R. Selten, por su tesis sobre la teoría de los juegos. La vida del profesor Nash fue llevada al cine en el año 2001: "Una mente brillante”, dirigida por Ron Howard y protagonizada por Russell Crowe y Jennifer Connelly. Desde niño, John se mostró retraído, dedicado a la lectura, el estudio y la soledad. En su etapa universitaria empezaron a manifestarse los síntomas de la enfermedad mental del grupo de las psicosis denominada esquizofrenia (disociación específica de las funciones psíquicas, que se plasma en una doble personalidad). Con el paso del tiempo, la enfermedad se fue agravando hasta 
hacerse crónica. Su vida familiar y profesional se vio seriamente afectada, con periodos de profunda crisis, augurando un futuro sombrío, incierto y triste. El apoyo incondicional de su esposa, su fuerza de voluntad y, sobre todo, su denodada dedicación investigadora, lograron lo que parecía imposible: el control de la enfermedad y, por consiguiente, la posibilidad de llevar una vida digna, dedicado a su familia y a la actividad docente. Otro ejemplo es el libro de Lou Marinoff, Más Platón y menos Prozac. Filosofía para la vida cotidiana que, partiendo de la filosofía práctica, enseña a encontrar en las ideas filosóficas, soluciones para los trastornos psicológicos específicos y los problemas de diversa índole. En el aula, no es cuestión de trabajar solo con la cabeza, sino también con todo el ser. Como se suele decir en el lenguaje coloquial: "hay que poner toda la carne en el asador". Hay que arriesgarse por entero y no parcial o fragmentariamente. Puntualiza Barlow: "La enseñanza -me parece- es un acto de la persona entera, un don de todo el ser, un compromiso" (Barlow, 1988: 47).

\section{Filosofia y experiencias humanas}

Cuando estamos ante un estanque, cuyas aguas están sucias, tenemos que hacer un esfuerzo visual (que será infructuoso) para ver, o más exactamente, atisbar la vegetación acuática y los peces y tortugas y demás especies que puedan habitar en él. Hace falta cambiar el agua y que fluya para evitar la sedimentación de los residuos orgánicos producidos por los seres vivos. Pues bien, la filosofía tiene la función, en nuestra modesta opinión, de aclarar el estanque de la vida humana para ver con claridad y, en cierto modo, para apreciar el sentido de las cosas y su alcance. La filosofía tiene que clarificar (purificar, oxigenar y diafanizar) realidades de la experiencia humana tales como la ontología, la naturaleza, el conocimiento, la existencia 
corporal, la intersubjetividad, el lenguaje articulado, la estética, la experiencia religiosa (fenomenología de la religión), la axiología-ética, etcétera. Dicho de otra forma: tiene que 'descorrer el velo', revelar aquella realidad que es incomprensible, borrosa e incompleta.

En una ocasión, la madre de Ignatius le replicó a su hijo: "A veces, hay que ver a una persona en su medio real para comprenderla" (Kennedy Toole, 1992: 337). "En su medio", es decir, en contacto directo con la realidad y no de manera figurada o sesgada. Hay que ayudar al alumno (niño, adolescente o joven) a mirar las experiencias humanas marcando cierta distancia ante las mismas [objetividad] pero, a la par, manteniéndose dentro de esas experiencias [subjetividad]. Lo que mira no es algo distinto a él (en cuanto a la experiencia en sí) y, sin embargo, es algo novedoso en él (en cuanto al sentido, la articulación y la dirección de dicha experiencia). El ejemplo de una experiencia humana ilustrará la aseveración anterior: el conocimiento. Los alumnos no se sienten 'perdidos' con el vocablo 'conocimiento'. A su estilo y, tal vez, echando mano a la experiencia personal, serán capaces de definir lo que significa: "aquellas cosas que tienen que ver con las personas o el mundo, que se sabe por la vía de la experiencia o por el estudio". Una definición acertada aunque, más de uno, la calificaría de imprecisa. Lo cierto es que el alumno no define el término como algo 'extrínseco' (fuera de él) sino, todo lo contrario, como una experiencia 'intrínseca' (en él). A través de la enseñanza de filosofía, el alumno aprenderá nuevos elementos del conocimiento: una definición más académica ("Aprehensión intelectual de un objeto"); la disciplina filosófica denominada 'Gnoseología' (teoría del conocimiento); el proceso de conocimiento en el que intervienen el objeto (lo conocible), el sujeto (el conocedor) y la cosa conocida (el conocimiento); el tránsito de los objetos exteriores a los conceptos interiores; final- 
mente, los criterios que han de utilizarse para garantizar la verdad o la falsedad del conocimiento, sus condiciones y limitaciones.

Una consecuencia feliz y alentadora que se desprende del binomio filosofía y experiencias humanas, afecta al alumno: la operación de 'salir de sí', descentrarse, para centrarse en el mundo donde está y, especialmente, en las personas con quienes ha de construir su existencia.

Tomar postura y voluntad crítica, en relación con todo el ámbito de la experiencia humana

El paso siguiente es encaminar al alumno hacia la actitud crítica que, por supuesto, nada tiene que ver con la rebeldía, el escepticismo, el prejuicio y la práctica de ser criticón, sino con el recurso legítimo y razonable de guardarse del error y, así, el pensamiento se abra camino en dirección a la verdad. En otras palabras, a la luz de la sabiduría popular, evitar que le den 'gato por liebre'.

La voluntad crítica (o el espíritu crítico) exige, reclama, nitidez en los conceptos y sentido adecuado en la utilización de los mismos. Afirma el profesor López Quintás al respecto: "Nada más importante en la formación humana que acostumbrarse a pensar, hablar y escribir con el mayor rigor. Rigor significa aquí adecuación a la realidad. Pero la realidad presenta diversos planos conforme a la dignidad o rango de los distintos seres" (Quintás, 1998: 122-123). Recurramos nuevamente al ejemplo. Imaginemos que el profesor está exponiendo la disciplina filosófica por antonomasia: la metafísica. Después de varias clases, un alumno decide expresar su parecer sobre el tema y exclama: “¡Esto es un rollo! ¡Qué aburrimiento! No entiendo ni una jota. ¿Para qué sirve esta ensalada de conceptos ontológicos: el ente, la sustancia, el accidente, la esencia, las propiedades trascendentales? ¿Qué tienen que ver estas co- 
sas con nosotros y con el mundo?”. El profesor le pregunta: “¿Cuál es tu argumento para pensar así, para rechazar categóricamente la metafísica?”. El alumno responde: ¿Argumento? ¡A cuento de qué! ¡Es lo que pienso y es lo que siento!”. ¿Hay que deducir que el alumno se ha pasado de la raya, que es un maleducado, un patán recalcitrante? ¡No! El problema no estriba tanto en su animadversión hacia la metafísica (es probable que todos, siendo estudiantes en la escuela, el colegio o la universidad, hayamos sentido repulsión o antipatía hacia alguna asignatura). El problema, o mejor, lo que ha de preocuparle al profesor, es la incapacidad o dejadez del alumno por fundamentar su opinión. No es viable ni mucho menos razonable. Podemos estar o no de acuerdo con el sentido y la importancia de la metafísica en la vida del hombre, pero, lo que hay que tener claro son las razones dadas a favor o en contra de dicha disciplina. No es correcto replicar a la pregunta "¿por qué no consideras significativa la metafísica?”, en los siguientes términos: "porque su contenido me da náuseas, vértigo y sueño". Aun siendo verdad, hay que razonar la respuesta y no despotricar sin ton ni son ( $\sin$ causa).

El alumno ha de superar el sofisma secundum quid: la generalización precipitada de algunas observaciones particulares. "Esta tipología de entes es pura abstracción, un laberinto mental que te aleja de la vida real. Por consiguiente: la metafísica en particular y la filosofía en general no son disciplinas con sentido para la vida humana”. El profesor tiene que 'agacharse' a la altura del alumno ( $s i n$ dejar por ello de seguir siendo profesor) con el fin de comprender su actitud y ayudarle a contemplar la materia desde una perspectiva didáctica más favorable. El profesor interviene como puente que une la aportación de un filósofo con las inquietudes del alumno. Merece la pena puntualizar que el filósofo no está obligado a presentar su pensamiento a ras del suelo, ni tampoco elevarlo sobre las 
nubes. "Con el fin de convertir a la filosofía en una viva fuente de inspiración para la época actual, el filósofo debe, pues, evitar dos riesgos: el de degradar la filosofía tratando a toda costa de colocarla al alcance del público, y el de asfixiarla manteniéndola confinada en tantas torres de marfil como cabezas de filósofos hay en el planeta" (Ferrater Mora, 1963: 171). Como ya indicamos en el apartado 'el desafío del alumno', el profesor ha de esforzarse por hacer la filosofía inteligible y apasionante.

\section{Capacidad para interrogar en orden a buscar una solución y no suscitar problemas insolubles}

Se cuenta que un filósofo había dedicado muchos años a indagar sobre el sentido de la vida. Para ello, había leído libros, consultado a sus colegas, había reflexionado y escrito sin que se sintiera del todo satisfecho con las respuestas obtenidas. Un día, vio a su hija de cinco años en el jardín, jugando plácidamente. Se acercó a ella y le preguntó: “Hija, ¿para qué estás en el mundo?”. Sonriéndole, la niña respondió de inmediato: "para amarte a ti papá". Una respuesta sencilla que contenía una verdad inteligente y auténtica: el sentido de la existencia tiene que ver con el valor de la persona y, más concretamente, con la necesidad de ser amado y la necesidad de amar.

La filosofía se caracteriza por el 'arte de formular preguntas' y, por supuesto, de buscar respuestas a las mismas. Las preguntas emergen de la experiencia cotidiana y precientífica del hombre en su 'estar en el mundo' y, por consiguiente, desde el punto de vista metodológico, con la admiración y la duda ${ }^{7}$. Se establece una relación entre la experiencia cotidiana y la propensión humana de formular interrogantes esenciales que tienen que ver con el sentido de la vida, el por qué de las cosas y su finalidad. A su manera, los alumnos también formulan preguntas sobre lo que 
acontece en el mundo donde viven. Las preguntas no son para suscitar problemas insolubles, para complicarnos la vida con planteamientos subjetivos que rayan lo narcisista, sino con miras a buscar una solución (y comprender mejor la vida). De hecho, no estamos en el mundo para ser problema, sino para afrontar los problemas que existen (en número, diversidad y efectos) y ser solución en coordinación con los demás. Las preguntas permiten bucear en la realidad, para no quedarnos simplemente con lo que vemos tal cual, como el submarinista que está en alta mar, no con el propósito de contemplar el agua en la superficie, sino para adentrarse en sus profundidades y descubrir, admirar y conocer la vida que esconde en sus entrañas. Todo el entramado intelectual (intuición, interrogante, opinión [idea], hipótesis, argumentación, juicio crítico) está dirigido a la consecución de la verdad, como hemos apuntado anteriormente.

\section{Calidad de vida humana}

Y la verdad de las cosas, el captar su sentido, perfecciona la vida humana, favorece la humanización de la ciencia, de la cultura, de la economía, de la política, en fin, de la sociedad. El filósofo honesto no se exprime el cerebro con la ambición malsana de ser dueño de la verdad, de sobresalir, de alcanzar poder, prestigio y dinero. El filósofo honesto se dedica a la actividad filosófica no tanto por 'impulso humano determinante al saber', sino más bien por la disposición de servir a la sociedad. No es por jactancia personal, sino en beneficio de la humanidad. La filosofía, en este sentido, viene a ser algo así como una acequia que lleva el agua del pensamiento, sin la finalidad de anegar las esperanzas de los hombres de un mundo mejor, sino para 'dar de beber' a los que tienen sed del sentido de la existencia, del mundo y de la historia, para regar la tierra 
reseca de identidad, significado, dinamismo y dirección. La razón, en sintonía con la fe, ha de aportar luz, allí donde las tinieblas engendran barbarie, desolación y sufrimiento.

Enseñanza y aprendizaje son las dos caras de la moneda 'humanización'. Si falta una de las caras, sencillamente, no habría moneda. No es una moneda para 'pagar', sino una moneda ('divisa') para 'recibir', con la que participar responsablemente en el mundo, con sus luces y sombras, sus fortalezas y debilidades, sus éxitos y fracasos. El mundo en el que estamos temporalmente y en donde, pese a todo, estamos llamados a construir una vida digna, entrañable y creativa. Es fácil señalar los errores, las deficiencias, las contradicciones, las aporías o los sofismas. A ese primer paso (realismo histórico), le sigue otro: buscar soluciones. Y la búsqueda, en filosofía y en las demás disciplinas, no es a lo llanero solitario sino 'con los otros'. En vez de precipitarse a criticar el pensamiento de un filósofo cualquiera, hay que molestarse por conocer lo que dice, comprender lo que argumenta y reconocer sus posibles aciertos, agudeza intelectual al servicio de la familia humana.

La filosofía no es fruto de la 'holgazanería' porque, si fuera así, habría que poner en entredicho o 'en cuarentena' sus comentarios, afirmaciones y conclusiones.

\section{Transparencia en el ser, credibilidad en el obrar}

Filosofía teórica y filosofía práctica son las dos alas de la filosofía sistemática, que necesitan articularse 'sinfónicamente' para emprender el vuelo hacia la verdad. La historia de la filosofía recoge toda una constante y apasionante migración de ideas, pensamientos, escuelas, de distintas culturas, épocas y contextos. En todos ellos, mutatis mutandis, descansa la aspiración de que la actividad intelectual vaya de la mano con el comportamiento humano. 
El alumno, guiado por la experiencia y el conocimiento del profesor, tiene que ser capaz de percibir esta relación primordial y estrecha entre el ser y el actuar. Cuanto mejor seamos, mejor obraremos y, por ende, seremos creíbles, en especial, no por lo que digamos o hagamos sino, esencialmente, por lo que somos (personas) y desde dónde nos situamos (en el mundo y no ante el mundo; con los demás, y no por encima de los demás; como humildes servidores del saber, y no como dueños absolutos del conocimiento: como colaboradores en la búsqueda y comprensión de la realidad, y no como aristócratas solitarios que monopolizan el depósito de verdades). ¿Utópico, ingrávido, insostenible e infructuoso este enfoque y estilo de enseñar y aprender filosofía, cuando el alumno del siglo XXI parece estar más identificado (y capacitado) con otras materias que tienen que ver como lo técnico, con la realidad 'virtual', con la eficiencia del porcentaje, la variedad de datos y el atractivo que despiertan los avances científicos (más por lo que ilustran, que por lo que enseñan? Lo sabemos: el arte de enseñar filosofía (nunca mejor dicho) no consiste solo en que el alumno sepa situarse históricamente en el contexto de la filosofía, distinguir los diferentes sistemas, desde la claridad de los conceptos y la comprensión de sus contenidos. Ese tapiz de pensamientos, entretejido con hebras de diferentes tamaños y colores, no es para que el alumno lo contemple como una obra artística del pasado que nada tiene que decir en el presente. El tapiz filosófico, curiosamente, sigue teniendo vida, si se nos permite la expresión. Vida en cuanto a lo que pueda decir, iluminar, en la existencia del hombre. Hay personas (del presente) que reconocen haber recibido un importante 'apoyo terapéutico' al escuchar la música de célebres compositores como Bach, Beethoven, Mozart o Vivaldi (del pasado). ¿No puede suceder lo mismo con los filósofos? ¿No es esa la 
pretensión, precisamente, del libro de Lou Marinoff, citado en este artículo?

El ejercicio de la reflexión, para que alcance la altitud conveniente, ha de desembocar en acción, en el compromiso existencial, en una comprensión del hombre y del mundo, más que en un sentido exclusivamente científico, en un sentido pedagógico que comprometa, implique al alumno en el quehacer filosófico, en contacto con la realidad variopinta, vibrante y versátil ${ }^{8}$.

\section{Conclusión}

Bruno, niño de nueve años, cae en la cuenta de algo aparentemente insustancial pero que, en ese instante, al reparar en ello, él mismo se sorprende de su despiste, ceguera o ignorancia. "Es curioso que nunca me haya preguntado qué hace esa gente ahí -pensó el niño-. Y es curioso que con todas las veces que los soldados van allí -había visto incluso a Padre pasar al otro lado en muchas ocasiones-, nunca hayan invitado a nadie del otro lado a venir a esta casa" (Boyne, 2007: 102). Su padre era oficial alemán con la tarea 'importante’ y 'delicada' (¡cínica y malévola!) de dirigir un campo de concentración en la ciudad polaca de Auschwitz donde, cada día, morían judíos en el interior de la cámara de gas, al inhalar el fluido aeriforme letal. Los 'del otro lado' eran los judíos que, como Bruno pudo comprobar posteriormente (cuando incursionó en el otro lado de la alambrada, haciéndose pasar por un niño judío), vivían en unas condiciones infrahumanas y degradantes. La pregunta es, de por sí, un acto del pensar, un planteamiento inteligente acerca de un dato de la vida: el padre de Bruno pasaba a su antojo al campo de concentración; en cambio, a los que estaban allí, no se les permitía 'salir del campo', a no ser que fuera por una razón de ín- 
dole práctica (una actividad doméstica o manual). Y, por supuesto, nunca era para visitar a Bruno en su propia casa. La filosofía ayuda a cultivar esta 'sensibilidad humana' para que no aprobemos como normal lo que a todas luces está privado de sensatez, justicia y humanidad. La célebre película escrita, dirigida y protagonizada por Charles Chaplin (El gran dictador, 1940), recoge el discurso final, elocuente y profundo, pronunciado por el protagonista (el barbero judío que tenía un parecido físico con el ambicioso militar Astolfo Hynkel). En una parte del mismo declara:

¡Soldados! ¡No os entreguéis a esos bestias, que os desprecian, que os esclavizan, que gobierna vuestras vidas; decidles lo que hay que hacer, lo que hay que pensar y lo que hay que sentir! Que os obligan a hacer la instrucción, que os tienen a media ración, que os tratan como a ganado y os utilizan como carne de cañón. ¡No os entreguéis a esos hombres desnaturalizados, a esos hombres-máquinas con inteligencia y corazones de máquinas! ¡Vosotros no sois máquinas! ¡Sois hombres! ¡Con el amor de la humanidad en vuestros corazones!?.

A modo de recapitulación, recogemos las ideas principales de lo expuesto:

1. La clase de filosofía ha de desarrollarse desde la categoría de encuentro, entre el alumno y el profesor, situados en un mismo nivel humano, con el fin de evitar una concepción jerárquica en el proceso didáctico enseñanza-aprendizaje.

2. Ambos interlocutores tratan un asunto común: la filosofía. Interactúan en torno a esta disciplina.

3. El reto del docente es despertar en el alumno el gusto por la filosofía. 
4. El desafío del alumno es, a su vez, estimular en el docente la articulación del rigor metodológico con la creatividad pedagógica.

5. Alumno y profesor, más que caminar en paralelo (puesto que nunca llegarían a encontrarse), caminan juntos, hombro con hombro, por así decirlo, en la búsqueda corresponsable de la verdad.

6. La filosofía tiene mucho que ver con las experiencias humanas, aunque se caracterice por ser una ciencia universal que trata del conocimiento de las cosas (investiga la realidad total por su esencia, propiedades, causas y efectos; clasificación del mundo incluyendo al hombre).

7. En la enseñanza de filosofía, el alumno tiene que sentirse implicado a tomar postura y a la voluntad crítica, en relación con todo el ámbito de la experiencia humana.

8. El que enseña (docente) como el que aprende (discente) han de familiarizarse con la actividad de formular preguntas en orden a buscar una solución y no tanto elaborar problemas insolubles.

9. El estudio de la filosofía tiene mucho que ver con la vida humana $y$, desde una mirada prospectiva, contribuye a mejorar la presencia del hombre en el mundo, su relación con los demás, su estar aquí y ahora, la dinámica de ser proyecto (lat. proiectus = 'lanzado a').

10. La consecuencia inmediata de enseñar y aprender filosofía recae en el alumno, de manera especial, pero sin restar valor a la actuación del profesor. Ambos, han de conducirse hacia la transparencia en el ser $y$, por ende, a la credibilidad en el obrar. 
Es un decálogo que, desde luego, no está completo y, por consiguiente, no es cerrado sino flexible, abierto a nuevas matizaciones, lecturas e incluso correcciones porque no agota el tema de enseñar y aprender filosofía, al igual que tampoco este artículo. El presente trabajo es, lisa y llanamente, una perspectiva, un ángulo desde el cual mirar 'la aldea filosofía', con sus calles, plazas, parques, avenidas y, sobre todo, nombres y pensamientos del ayer y del hoy. Aplicando la autocrítica reconocemos que, tal vez, han quedado algunas cosas en el tintero como, por ejemplo, el 'personaje' discreto pero significativo como es la familia; el diálogo entre fe y razón, teología y filosofía; indicar el punto de inflexión entre enseñar y aprender; comentar, siquiera brevemente, los rasgos comunes de los jóvenes inmersos en un mundo globalizado, la relación (si la hay y cómo y a qué nivel) entre filosofía y la sociedad técnico-científica. Por otra parte, se podría haber sacado punta a lo concerniente al desafío del profesor y del alumno, a las actitudes de cada personaje, a las bondades (que las hay) al recurso de la imagen y el sonido, el valor de la verdad, en fin, al arte de interrogar, para evitar malentendidos y conclusiones fuera de tono (o de juego). La vida no se reduce, desde luego, a pensar, sino también a amar. Lo cierto es que un amor sin cabeza puede ser sumamente peligroso. Seguro que el lector enumerará otras limitaciones, deficiencias y disonancias del artículo, señal que lo ha leído con los ojos del corazón en sintonía con el entendimiento.

Con todo, como habíamos anticipado en el inicio del artículo, proponemos la siguiente secuencia didáctica que puede ser una guía en la ardua, apremiante y valiosa actividad de enseñar y aprender filosofía. Nos inspiramos en un episodio bíblico: Jesús y la samaritana (Jn 4, 1-30). Es un episodio entrañable, diáfano y aleccionador. En él descubrimos, sin necesidad de forzar el texto, una secuencia sencilla y práctica. 
Encuentro. Jesús es quien espera 'sentado junto al pozo' a la samaritana, y toma la iniciativa de entablar conversación con ella. Si bien el profesor es el que 'entra en el aula' donde le esperan los alumnos, él tiene que ingresar con la disposición interior de 'recibir a sus alumnos' y de dirigirse a ellos en unos términos que infundan confianza (de familiaridad en vez de autoridad), propiciando la dinámica del encuentro.

Comunicación. La manera con la que Jesús inicia el encuentro con la samaritana (una orden: "Dame de beber"), lejos de ser altanera, revela un rasgo eminentemente humano: la menesterosidad. Jesús se presenta humilde y honestamente frágil (cansado, sediento) y necesitado de ayuda. Precisamente, es esa indigencia la que pone en marcha la comunicación entre él y ella, ella y él, que, por cierto, no tuvo un buen inicio debido a la samaritana (se mostró esquiva y hostil, pero no rehusó el diálogo). El profesor de filosofía facilitaría la comunicación con el alumno si en vez de dárselas de sabelotodo, reconociera sus limitaciones $y$, por ende, valorara lo que podría aprender del alumno, para perfeccionar sus conocimientos, en contacto con los 'signos de los tiempos' actuales. La clase, en vez de consistir en un monólogo gris, etéreo y anodino (un esperpento), propiciaría el diálogo cercano, espontáneo y profundo. ¡Para enseñar filosofía no hace falta poner cara larga ni tampoco hacerse el gracioso!

Creatividad. Jesús no coloca el listón a una altura difícil de superar por la samaritana sino, más bien, teniendo en cuenta la situación de ella (humano-espiritual). Parte de algo concreto (el agua) para, progresivamente, acompañar a la samaritana a otra realidad superior y esencial. No la presiona a que entienda rápido, sino que se acomoda a su ritmo y, con ella, hace camino hacia el descubrimiento de la verdad. En este sentido, Jesús no aturde a la samaritana con una cascada de palabras. Es claro, breve y preciso. 
Por su parte, no estaría de más que el profesor de filosofía aplicara en sus clases el conocido adagio latino: Non multa, sed multum (no tanto la cantidad como la cualidad). El alumno, tampoco tendría que explayarse en escribir o hablar muchas cosas de la materia para no transmitir nada. La creatividad exige no perderse en el laberinto de la verborrea o galimatías, e ir de menos a más, de lo simple a lo complejo, de lo sensible a lo intelectual.

Correspondencia. A medida que avanza el diálogo, la samaritana se siente más a gusto, participa de lleno en la conversación. Atrás quedaron los prejuicios, el desaire y la suspicacia. Curiosamente, en dos ocasiones ella misma expresa a Jesús: a. Una orden: le pide que le dé del agua que Jesús le ofrece ("Señor, dame de esa agua para que no tenga sed y no tenga que venir aquí a sacarla"), confundiendo el 'agua viva' de Jesús con el agua dulce del pozo; b.. Una confesión: su insatisfacción afectiva (ha tenido cinco maridos y, actualmente, cohabita con el sexto). El alumno tiene que participar en la clase, admitir que el aprendizaje es con el profesor y con sus compañeros, y no prescindiendo de ellos; que la filosofía es una herramienta válida para el conocimiento del mundo pero también, para el autoconocimiento.

Comprensión. En ningún momento Jesús juzga a la samaritana, ni mucho menos la condena, por su ignorancia religiosa y por su dejadez moral en la vivencia de su afectividad-sexualidad. En Jesús hay un elocuente respeto y una acogida incondicional. Ni el profesor tiene que machacar al alumno con expresiones tales como "eres un asno", "lo que acabas de decir es una estulticia", "estás a años luz de aprender filosofía", y cosas parecidas; ni tampoco el alumno tiene derecho a descalificar al profesor con expresiones de mal gusto: "es un satélite fuera de órbita", “¡atención que viene la lechuza volando!”, "la filosofía es un somnífero”, “¿los filósofos?, ¡una pandilla de gandules!, 
"esta asignatura es sobreabundancia de ideas y carestía de acciones".

Verdad. Jesús condujo a la samaritana al descubrimiento de la verdad. El profesor ha de acompañar al alumno 'a la verdad' y no 'a su verdad'. El alumno, por su parte, podría manifestar 'su verdad' $y$, con humildad intelectual, completarla y rectificarla con la verdad objetiva.

Transformación. El evangelista relata que la samaritana "dejó su cántaro, se fue al pueblo". El fruto del encuentro fue la conversión de ella y la urgencia de compartir a los demás la experiencia vivida. En el alumno, la transformación interior progresa a medida que va comprendiendo la asignatura de filosofía, al darse cuenta que es un recurso válido para alcanzar madurez y, así, superar la tendencia de resolver los desafíos personales o proceder en la convivencia diaria desde el horizonte de la reflexión ('inteligencia emocional') y no a golpe de un comportamiento impulsivo.

De esta secuencia se desprende una importante conclusión: más que enseñar y aprender filosofía desde la simpatía, se trata de dirigir el proceso didáctico desde la empatía (o endopatía). Con la primera alternativa, es fácil desviarse al terreno de lo emotivo, a una enseñanza maquillada con el cosmético de lo posible. En cambio, con la segunda modalidad, se sigue la 'hoja de ruta' de lo reflexivo, enseñando filosofía el profesor y aprendiendo el alumno en sintonía recíproca, ahondando en los interrogantes esenciales que tienen que ver con la realidad poliédrica, polisémica y polifónica. La empatía consiste en situarse 'en el otro', por así decirlo, adentrarse en su cosmovisión para que con él, a su vez, contemplar la realidad. Va a la raíz del hombre, a lo que le sostiene, dota de sentido y dirección a su existir. 


\section{Notas}

1 Un esquema más completo de los saberes filosóficos: 1 . Ser: campo de la objetividad: a. Filosofía de la Naturaleza: su objeto material es la totalidad de los entes materiales 'mutables' (pueden cambiar [dejar de ser] y 'llegar a ser de otra manera'); b. Metafísica - Ontología. 2. Hombre: campo de la subjetividad: a. Psicología; Antropología filosófica; Epistemología [conocimiento científico]; Gnoseología [teoría del conocimiento]; Lógica. 3. Valor moral de las acciones humanas: Ética. 4. Trascendencia: Teodicea.

2 Merece la pena recoger la siguiente cita de Millán Puelles: El ocuparse con los temas que afectan a las ultimidades de la existencia representa, de suyo, aunque solo alcanzara un valor meramente formal, trascender nuestra vida cotidiana, levantar el espíritu hacia un dominio en que ampliamente se desborda el condicionamiento sensible de los negocios de nuestro vivir. La admiración que da lugar a la filosofía nos hace suspender por un momento la ajetreada ocupación en que nuestro ser se dispersa y afana, y viene a colocarlo bajo un interrogante en que el hombre se torna sobre sí. La forma más frecuente de filosofar, la que en rigor no falta a ningún hombre, es la que consiste en preguntarse por el sentido total de todo eso que hacemos y deshacemos en la faena de nuestra vida. Nuestro ser necesita aclararse el valor y sentido de su propio operar. Y al recogerse en la meditación de estos temas, trasciende la dispersión de su diario vivir en el plano sensible y material y se libera siquiera sea por un momento, del peso de nuestro cuerpo sobre la tierra. (Millán Puelles, 1972: 36).

3 El camino que se recorre comienza con la intuición, pasa por la idea, continua con el juicio hipotético y desemboca en el juicio crítico por el razonamiento deductivo (proceso interior) e inductivo (proceso sensible). El hombre parte de los sentidos pero, a su vez, reflexiona sobre ellos. Como reconoce Marinoff: "La experiencia es una gran maestra, pero también precisamos reflexionar sobre nuestras experiencias. Necesitamos pensar con una postura crítica, buscando pautas de conducta y situándolo todo en el contexto general para abrirnos camino en la vida" (Marinoff, 2000: 18). En nota a pie de página Morin dice que "la clase debe ser el lugar de aprendizaje del debate argumentado, de las reglas necesarias para la discusión, de la toma de conciencia de las necesidades y de los procesos de comprensión del pensamiento del los demás, de la escucha y del respeto de las voces minoritarias y marginales" (Morin, 2003: 106). 
4 Julio Perelló señala las siguientes capacidades que tendría que desarrollar el alumno: escolaridad previa; madurez personal [intelectual, afectiva y vital]; acogida de la filosofía superando la actitud de prejuicio sobre la misma (cfr. Perelló, 2008: 165-166).

5 Lo apasionante no es enseñar a los alumnos, sino que ellos nos enseñen. Según uno de los grafitti del patio de la Sorbona: "Todo enseñante es enseñado, todo enseñado es enseñante". Si el maestro es para sus discípulos un despertador atento a sus reacciones y no una esfinge, si sabe escuchar antes de juzgar, descubre en germen riquezas insospechadas en los seres aparentemente más desesperantes. [...] Un mocito de doce años me hizo reflexionar un día más que muchos filósofos: 'Actúo un poco a lo pulga, cuando cae es para dar otro brinco. Después de una tontería, yo trato siempre de mejorar.... (Barlow, 1988: 140 y 141).

6 Se distinguen dos sentidos del término 'verdad': 1. Para referirse a una proposición (verdad lógica o semántica): una proposición (juicio intelectual) consta de uno de los valores lógicos: verdad o falsedad; 2. Para referirse a un realidad (verdad gnoseológica): una realidad es verdadera a diferencia de 'aparente', 'ilusoria', etcétera. Estaría por un lado la adecuación del enunciado (entendimiento) con la cosa o la realidad (ser) [adaequatio rei et intellectus] y, por el otro, el consentimiento intelectual sobre esta adecuación. Otras clases de verdad: la verdad metafísica (u ontológica): cada ente es verdadero ontológicamente siempre que existe (en 'lo que es', en el ente mismo como existente); la verdad ética; la verdad epistemológica. El Papa Juan Pablo II dice que "el hombre es el único ser en toda la creación visible que no solo es capaz de saber, sino que también que sabe, y por eso se interesa por la verdad real de lo que se le presenta" (Juan Pablo II, 1998: n. 25).

7 En los números 1 y 4 de la Carta Encíclica sobre las relaciones entre Fe y razón, el Papa Juan Pablo II hace mención al dinamismo dialéctico que se da entre la experiencia cotidiana y la inclinación humana a formular interrogantes esenciales que tienen que ver con el sentido de la vida, el por qué de las cosas y su finalidad. "Son preguntas que tienen su origen común en la necesidad de sentido que desde siempre acucia el corazón del hombre: de la respuesta que se dé a tales preguntas, en efecto, depende la orientación que se dé a la existencia" (Juan Pablo II, 1998: n. 1). El planteamiento de Morin converge con la cita anterior: "La educación del futuro deberá ser una enseñanza primera y universal centrada en la condición humana. [...] Conocer lo humano es, principalmente, situarlo en el universo y a la vez separarlo de él” (Morin, 2003: 47). "La educación 
debe favorecer la aptitud natural de la mente para hacer y resolver preguntas esenciales y correlativamente estimular el empleo total de la inteligencia general” (Morin, 2003: 40).

8 Lo que importa no es implantar debates, exposiciones en vez de clases magistrales o explicaciones de textos aburridos. Lo que importa es que tales ejercicios preparen realmente a nuestros alumnos para su oficio de hombres. Todo esto lo sentía confusamente, pero es bueno poder formularlo claramente. No se trata de un sueño. Habrá que repetirlo a tiempo y a destiempo, y sobre todo, vivirlo diariamente. (Barlow, 1988: 66).

9 http://www.msc.scouts-es.net/kipling/biblioteca/dictador.htm〉. 17 de febrero de 2011.

\section{Bibliografía}

\section{Textos}

Barlow, Michel

1988 Diario de un profesor novato. Salamanca: Ed. Sígueme. [5a edición].

Batista, Joao

2007 Saber pensar. Introducción a la vida intelectual. Madrid: San Pablo.

Boyne, John

2007 El niño con el pijama de rayas. Barcelona: Ed. Salamandra. [23a edición].

Estermann, Josef

2000 Filosofía sistemática. Curso integral de filosofía desde América latina. Tomo I. Quito: Ed. Abya-Yala.

Ferrater, José

1994 Diccionario de Filosofía. Tomo II. Barcelona: Editorial Ariel.

1963 La Filosofía en el mundo de hoy. Madrid: revista de Occidente. [2a edición].

Juan Pablo II

1998 Carta Encíclica sobre las relaciones entre Fe y Razón, Fides et ratio.

López, Alfonso

1998 La revolución oculta. Manipulación del lenguaje y subversión de valores. Madrid: PPC. 
Maceiras, Manuel

1994 Para comprender la filosofía como reflexión hoy. Estella (Navarra): Editorial Verbo Divino.

Marioff, Lou

2006 Más Platón y menos Prozac. Barcelona: Ediciones B. [6a reimpresión].

Millán, Antonio

1972 Fundamentos de Filosofía. Madrid: Ediciones RIALP. [8 edición].

Morin, Edgar

2003 Los siete saberes necesarios para la educación del futuro. Quito: Santillana.

Nicolas, Simonne

1991 Para comprender la Filosofía. Estella (Navarra): Editorial Verbo Divino.

\section{Artículos de revista}

Perelló, Julio

2008 Didáctica de la Filosofía. Quito: Colección SOPHIA, N. 4.

Anguita, Julio

2001 "Achusmamiento". "Los Domingos de ABC", 20.5.01, en: Cuaderno Misión Joven 293 [junio 2001]. Madrid.

\section{Referencias electrónicas}

http://www.msc.scouts-es.net/kipling/biblioteca/dictador.htm〉. 17 de febrero de 2011. 